moving screen image from the central tube of the paralleled group on to a screen approximately two feet square, with a tenfold magnification. This projected image was clearly visible from the back of the theatre although an accelerating voltage less than 2,000 was used on the tube. There was a striking contrast between the red fluorescence of the 'port' member of the group and the brilliant green of the 'starboard' tube.

In addition to experiments showing the applications of the oscillograph in radio research, Mr. Watson Watt exhibited a cinematograph film from the same field. The most novel section of the film might, he suggested, be called "Sturm über Europa", as it represented a single minute of the thunderstorm history of Europe. The places of origin of individual atmospherics-located by simultaneous cathode ray cinematography on a base-line Slough-Leucharswere indicated by bright flashes on a dark map of Europe, the timing of the flashes reproducing accurately the times of incidence of the individual atmos. pherics. The film showed that, within a single halfminute of recording, lightning flashes in mid-Atlantic, the North Sea, Denmark, Germany, Hungary, the Balkans, and France had contributed to the stream of atmospheries affecting Great Britain.

The lecture concluded with demonstrations of the variety of colour and duration of afterglow in screen materials, of the control of brightness by a Wehnelt cylinder, and of the applications of oscillographs fitted with Faraday cages to operations in which oscillographic response and relay control are combined.

The oscillographs used in the demonstrations were lent by the manufacturers, Messrs. A. C. Cossor, Ltd.

\section{Time Measurement: Old and New}

The last of the evening discourses at the Physical Society's exhibition was given by Mr. Hope-Jones on January 5 on "Time Measurement: Old and New". With the kind permission of Sir Henry Lyons, the director of the Science Museum, he was enabled to begin his lecture by exhibiting the Dover Castle clock, still going, although a relic of the fourteenth century. He showed lantern slides of the half-dozen known examples of this period, de Vick, Wells̃, Cassiobury, Salisbury, Porlock and Dinan, and expressed the hope that others will be found to have escaped the scrap-heap or restoration by a vandal clockmaker.

Mr. Hope-Jones traced the origin of the astronomical dial (a few of which survived the dissolution of the monasteries, such as Glastonbury, Wells, Wimborne and Hampton Court) from the Ptolemaic or geocentric conception of the universe, and showed models of Galileo's and Huyghens' escapements which harnessed the pendulum to wheelwork, thus bringing to a close the medieval period of 300 years during which the only known regulator for clocks and watches was the Foliot balance.

The halcyon days of English clock-making, inaugurated by Robert Hook, Harrison, Arnold and Earnshaw were discussed, and Mr. Hope-Jones deplored the fact that when Tompion and Graham were laid to rest in Westminster Abbey, the science of accurate time measurement died with them, or rather remained for two hundred years exactly in the condition in which they left it. $\mathrm{He}$ attributed this to the escapement, which had 'mesmerised' horology for so long, and showed how the "Synchronome" remontoire produces perfect freedom of the pendulum by coupling two together as 'master' and 'slave', a feat accomplished by Mr. Shortt's invention of the hit-and-miss synchroniser.

The extraordinary effects of the new standard of time-keeping set up by this clock were rapidly reviewed: how it caused the astronomers to invert their methods of producing rate charts; how it revealed nutation and necessitated a revision of the definition of time in the Nautical Almanac, and finally how the lunar period appeared in comparison with the crystal clock, although the change in the value of $G$ only affects the rate by $2 / 10,000$ sec. at maximum between lunar noon and midnight.

Prof. C. V. Boys has dubbed Mr. Hope-Jones as a modern Saint Athanasius, saying "this is the clock faith which, unless a man believe faithfully, he cannot be saved", subscribing to its articles himself, "with the possible reservation of some of its damnatory clauses". Whilst discouraging the use of the new synchronous motor clock for the time equipment of large buildings and institutions, $\mathrm{Mr}$. Hope-Jones proclaimed the engineers of the electric light and power stations as the future time-keepers of the nation, and described means of assisting them to keep their turbo-alternators running true to average Greenwich Mean Time.

\title{
Annual Meeting of the Mathematical Association
}

$\mathrm{T}$ HE annual meeting of the Mathematical Association was held in London at the Institute of Education on January 5 and 6 . The most notable features of the meeting were the presidential address by Prof. G. N. Watson and a discussion on "The Study of Statistics in a School Course". Prof. Watson's address had the mysterious title of "The Marquis and the Land Agent; a Tale of the Eighteenth Century". It was revealed as a topic from the history of mathematics. The speaker regretted that as a pure mathematician he could not speak on some popular subject from the 'real' world of the applied mathematician. Neither could a popular discourse be made on those researches into singular moduli which had engaged his leisure during the past two years. Pedagogical problems he regarded as of secondary importance. Only a historical subject remained.
The Marquis of the title was the Italian mathematician Guilio Carlo, Count Fagnano and Marquis de Toschi (1682-1766). English textbooks refer to him as Fagnano and mention a theorem concerning elliptic arcs. The 'land agent' was the English amateur, John Landen (1719-90) who was in the service of Earl Fitzwilliam from 1762 until 1788. His name is familiar in 'Landen's transformation' for an elliptic integral.

The tale uniting these two was their work on rectifying elliptic arcs and manipulating the corresponding integrals. In 1691, Bernoulli had discovered that it is possible to find arcs of a parabolic spiral which are of equal length but are not congruent. Fagnano obtained similar results for the lemniscate, and enunciated the general theorem that if $m$ is an integer, a quadrant of the lemniscate can be divided into $2^{m}$ or $3 \times 2^{m}$ or $5 \times 2^{m}$ equal parts. Amongst his results occur rudimentary forms of the addition ๑) 1933 Nature Publishing Group 
theorems for elliptic functions. Many years later, Jacobi referred to the day on which a copy of Fagnano's works reached Euler as "the birthday of elliptic functions". Landen, in his "Mathematical Lucubrations" (1755) studied transformations of integrals, showing considerable ingenuity in obtaining forms convenient for calculation. This aspect was developed later by Legendre, Gauss and Ivory. Prof. Watson mentioned, in passing, that, in his opinion, mathematicians of the eighteenth century handled the technique of the calculus more skilfully than the technique of analytical geometry.

After this pioneer work, development took place on two very different lines. Legendre developed the elaborate, but unfruitful calculus of integrating expressions giving elliptic arcs, whilst thirty years later Abel and Jacobi developed the vastly more important concept of inverting such integrals, thus founding the theory of doubly periodic functions. One of time's revenges lies here. The first mention of this concept of inversion is in a manuscript by Gauss dated January 8, 1797. Had Legendre known of this, he would never have given the last part of his life to the futile labour of his "Traité des fonctions elliptiques". Yet Gauss's failure to announce his result was directly due to his treatment at the hands of French mathematicians when his memoir on arithmetical numbers was refused publication by the French Academy. After their humiliating refusal to publish this work, Gauss was loath to take any steps to publish during his own lifetime.

Prof. Watson mentioned some recent approximate formulæ for the perimeter of an ellipse, due to Peano (1887) - a mathematician usually associated with very different studies-and Ramanujan (1914). In connexion with his address an unusually complete exhibition of books on elliptic functions, arranged chronologically, had been compiled by Prof. Neville.

The discussion on "The Study of Statistics in a School Course" was opened by Mr. F. Sandon, headmaster of Plymouth Grammar School, who presented the unpopular view that the subject could have no place in the normal course. He suggested that the capabilities of pupils are so various and the intrinsic difficulties of the subject so real that little value would result. Few teachers appear to know much of the subject. Statistical prineiples can be applied to modify some topics in the arithmetic course, such as the teaching of averages and graphs of statistics, but work beyond this, such as probability or correlation, is too difficult or laborious. Mr. Tuckey of Charterhouse and Mr. Wright of Winchester gave evidence flatly contradicting this. With an average middle school form, a course of two hours a week has proved possible and profitable at Charterhouse. Frequency curves, probability, dispersion and correlation have been studied with some seriousness. At Winchester, rather abler boys with no examination in prospect have covered a systematic textbook course as far as Spearman's "Foot-Rule" for measuring correlation. The balance of opinion of the meeting appeared to favour testing these opinions as to the possibility of teaching statistics in schools.

Other papers discussed various topics. Dr. Smart of Cambridge traced the history and importance of the precession of the equinoxes. Dealing with the importance of accuracy in observation, he mentioned the recent discovery of the work of the Rev. John Hornsby, an eighteenth century Oxford astronomer. From Hornsby's observations it is possible to obtain the data showing the motion of the perihelion of Mercury-a phenomenon that was not satisfactorily explained until the present century. Work in school was dealt with by several teachers. Mr. Boon of Dulwich pleaded for more use of side-tracks such as history and puzzles in elementary mathematies. Mr. Robson of Marlborough showed the possibilities of parametric representation in the specialist course. A keen discussion followed Mr. Siddons's paper on "Learning Theorems in Geometry". Mr. Siddons suggested that learning theorems is not valuable until pupils have some skill in solving riders. Mr. Piggott of Dartmouth put forward a more real method of teaching relative velocity than that current in textbooks. The device of 'reversing a velocity' was shown to be quite unnecessary. Finally, the Rev. D. B. Eperson of Sherborne concluded a most successful meeting with a diverting account of Lewis Carroll's work as mathematician.

\section{Annual Conference of the Geographical Association}

$\mathrm{T}$ HE annual conference of the Geographical Association was held at the London School of Economies on January 4-6, and at the Imperial Institute, South Kensington, on January 7. About five hundred members took part, provincial and Scottish branches being particularly well represented.

The retiring president, Dr. H. R. Mill, chose as the title for his presidential address "An. Approach to Geography". In fluent and easy language, yet with a precision too often absent from generalisations, he traced the progress of the modern concept of scientific geography. $\mathrm{He}$ emphasised the steady conquest by man of so many of the natural factors of his environment and the evolution of the world of to-day, which may thus be free and open to the movements of mankind. But man, in conquering the natural barriers, has erected in their stead artificial barriers in the form of frontiers with their tariff walls and innumerable other restrictions. Thus the geographer cannot ignore the new, though artificial, factors of the environment and his work must interlock with that of the economist. At the same time, the problem is complicated by the fact that geographical factors are becoming more and more important in that, with the world improvement of transport and communications, it no longer pays a country to attempt the production of a commodity for which it is geographically unsuited.

This function of the geographer in helping to provide solutions for the complicated problems of the present day was further emphasised by Sir John Russell in his lecture on "Modern Changes in the Sources of our Food Supplies". One of the speakers at the annual dinner referred to geography as the 'most human' of all the sciences and to the appropriateness of meeting in the School of Economics, which was represented at the dinner by its director, Sir William Beveridge. The benefits to be derived from collaboration with allied sciences was further emphasised by a joint meeting with the Le Play Society, when an account of studies in Yugoslavia - the result of party visits led by himself and Dr. L. D. Stamp-was given by Mr. Arthur Davies. The Association extended its welcome to Col. 